\title{
Avances y retrocesos en la aplicación jurisprudencial del Convenio Colectivo para Docentes de las Instituciones Universitarias Nacionales (Dec. 1.246/15)
}

Advances and Setbacks in the Jurisprudential Application of the Collective Agreement for Teachers of National University Institutions (Dec. 1.246/15)

Avanços e retrocessos na aplicação jurisprudencial do Acordo Coletivo para Professores das Instituições Universitárias Nacionais (Dec. 1.246/15)

Avancées et régressions dans à l'application jurisprudentielle de la convention collective des enseignants des institutions Universitaires Nationales (1 246/15 déc.)

国家大学教师集体协议的法理学应用的进展和挫折 (Dec. 1.246/15)

Pablo Octavio Cabral ${ }^{1}$ Universidad Nacional de La Plata

Revista Derechos en Acción ISSN 2525-1678/ e-ISSN 2525-1686

Año 4/No 12 Invierno 2019 (21 junio a 20 septiembre), 401-413

DOl: https://doi.org/10.24215/25251678e311

ORCID: https://orcid.org/0000-0001-5768-4958

Recibido: 19/08/2019

Aprobado: 01/09/2019

Resumen: En el presente trabajo se abordan los avances y retrocesos de la aplicación jurisprudencial del Convenio Colectivo para Docentes de

\footnotetext{
Abogado (UNLP), especialista en Derecho Administrativo y Administración Pública (UNLP), docente regular en la materia Derecho Administrativo II de la Facultad de Ciencias Jurídicas y Sociales de la UNLP (pablooctaviocabral@yahoo.com.ar).
} 
las Instituciones Universitarias Nacionales a la luz de tres sentencias judiciales, dos de la Corte Suprema de Justicia de la Nación y uno de la Cámara Federal de Corrientes, en los que se abordan cuestiones centrales alcanzadas por dicha normativa. Se destaca la decisión del máximo tribunal federal que reconoció expresamente que la potestad de las universidades para llevar a cabo su gestión en forma autónoma no puede convertirse en un obstáculo al ejercicio de los derechos consagrados por la Constitución Nacional a favor de los trabajadores que se refieren a la asociación sindical libre y democrática y a la posibilidad de concertar convenios colectivos de trabajo.

Palabras claves: Universidad pública- Convenio Colectivo de trabajojurisprudencia

Abstract: This paper addresses the advances and setbacks of the jurisprudential application of the Collective Agreement for Teachers of National University Institutions related to three judicial decisions (two of the Supreme Court of Justice of the Nation and one of the Federal Chamber of Currents) which address central issues reached by such legislations. We highlight the decision of the highest federal court that expressly recognized that the university potesta to carry out their management autonomously cannot become an obstacle to the exercise of the rights enshrined in the National Constitution in favor of workers who refer to free and democratic trade union association and the possibility of concluding collective bargaining agreements is noteworthy.

Keywords: Public University - Collective Bargaining Agreement - jurisprudence

Resumo: Neste artigo aborda-se os avanços e retrocessos da aplicação jurisprudencial do Acordo Coletivo para Professores das Instituições Universitárias Nacionais à luz de três sentenças judiciais, duas do Supremo Tribunal de Justiça da Nação e uma da Câmara Federal de Corrientes, nos que se abordam questões centrais alcançadas por aqueles regulamentos. Destaca-se a decisão do mais alto tribunal federal que expressamente reconheceu que o poder das universidades de realizar sua gestão autonomamente não pode se tornar um obstáculo ao exercício dos direitos consagrados pela Constituição Nacional em favor dos trabalhadores que se referem à associação sindical livre e democrática e à possibilidade de concluir acordos coletivos de trabalho. 
Palavras-chave: Universidade Pública - Acordo Coletivo de trabalho jurisprudência.

Résumé: Ce document traite des avancées et des régressions dans I'application jurisprudentielle de la convention collective des enseignants des institutions Universitaires Nationales à la lumière de trois sentences judiciaires, deux de la Cour Suprême de Justice de la Nation et une de la Chambre Fédérale de la province de Corrientes., dans lesquels sont abordés des questions centrales traitées par la dite norme. La décision de la Haute Cour fédérale qui a expressément reconnu que le pouvoir des universités d'assurer leur gestion de manière autonome ne peut devenir un obstacle à l'exercice des droits consacrés par la Constitution Nationale en faveur des travailleurs membres de l'Association syndicale libre et démocratique et à la possibilité de conclure des conventions collectives du travail

Mot-clés: Université publique - Convention Collective du travail - jurisprudence

摘要：本文根据三个司法判决，两个来自国家最高法院和一个来自 联邦商会的判决, 论述了国家大学教师集体协议的法理学应用的进 展和挫折. 解决了这些法规所涉及的核心问题. 最高联邦法院明确 承认大学自主管理其权力的决定不能成为行使国家宪法所赋予的 权利的障碍，有利于他们所指的工人自由民主工会协会和缔结集体 谈判协议的可能性.

关键字: 公立大学, 集体工作协议, 法理学

\section{Introducción}

Mediante la emisión por parte del Poder Ejecutivo de la Nación del Decreto $N^{o} 1.246 / 15$, publicado en el Boletín Oficial el 2 de julio de 2015, se incorporó al sistema universitario público nacional una norma obligatoria de carácter colectivo que lo integra y que establece un régimen de mayor protección de los trabajadores docentes universitarios. Los docentes que prestan funciones en Universidades Nacionales son trabajadores que deben, sin dudas, ser reconocidos como empleados 
públicos y que -por tal condición- son sujetos de especial protección por el ordenamiento jurídico nacional e internacional. Es decir, además de la garantía a la estabilidad prevista constitucionalmente, les son aplicables todos los principios protectorios que alcanzan a los trabajadores en nuestro país. ${ }^{2}$

En este documento abordaré tres fallos, dos de la Corte Suprema de Justicia de la Nación y uno de la Cámara Federal de Corrientes, en los que se abordan cuestiones centrales alcanzadas por el Convenio Colectivo para Docentes de las Instituciones Universitarias Nacionales.

\section{Derechos de los docentes interinos con designación vencida (CSJN, "Ryser"3)}

En este primer fallo veremos una interpretación restrictiva de los derechos de los trabajadores docentes universitarios, en el que el superior tribunal federal aplica criterios tradicionales de su propia jurisprudencia, ignorando la existencia de un régimen normativo aplicable y vigente al momento del dictado de la sentencia que establece un sistema de estabilidad protectorio de los trabajadores universitarios.

La Corte Suprema de Justicia de la Nación resolvió el caso presentado por un docente universitario con designación interina quien obtuvo su reincorporación al cargo hasta que se convoque al concurso público para cubrir dicho cargo, y sostuvo que toda designación interina de docentes universitarios se extingue de pleno derecho al final del plazo, sin que genere derecho a la renovación ni a la estabilidad. Para la Corte, un docente universitario con concurso vencido tras agotarse el

\footnotetext{
2 Ampliar en Cabral, P. O. (2017). El Convenio Colectivo para los Docentes de las Instituciones Universitarias Nacionales y su plena vigencia en la Facultad de Ciencias Jurídicas y Sociales de la UNLP. Derechos En Acción, (3). https://doi.org/10.24215/25251678e013.

3 CSJN, Fallos, 340:614, "Ryser, Walter Adolfo c/ Universidad Nacional de Catamarca s/ Apelación art. 32 ley 24.541", sent. de 03-V-2017, voto de los ministros Highton de Nolasco, Lorenzetti, Maqueda y Rosenkrantz, con remisión al dictamen de la Procuración General de la Nación.
} 
plazo de su designación interina no tiene derecho a la estabilidad en dicho cargo. Como veremos, en el caso, los jueces intervinientes no tuvieron en consideración los alcances y posibles implicancias de lo normado en el Convenio Colectivo de Docentes Universitarios de Instituciones Nacionales.

La Cámara Federal de Apelaciones de Tucumán había hecho lugar por mayoría a la petición del actor, condenando a la Universidad Nacional de Catamarca a reincorporarlo en el cargo que desempañaba como profesor interino adjunto de la Cátedra de Matemática I de la Facultad de Ciencias Económicas de dicha universidad, hasta tanto se convoque a concurso público de antecedentes y oposición para cubrir ese cargo, y abonarle salarios caídos.

La alzada clasificó dos tipos de categorías de docentes universitarios, los que obtuvieron su cargo por concurso (ordinarios) y que perdieron su regularidad por el vencimiento del plazo de designación y aquellos que fueron designados sin concurso (interinos), ubicando al accionante en la primera de las clasificaciones, resultando una categoría diferencial entre los docentes regulares y los interinos per se.

Para sentenciar en favor del docente consideró que la pérdida de la condición de profesor regular no derivaba de una acción propia sino de una omisión de la universidad en llamar a nuevo concurso para la cobertura del cargo antes del vencimiento del plazo de su designación. Por lo que, no correspondía hacerle cargar al profesor con las consecuencias de la omisión de la institución académica, quien tampoco invocó una causal objetiva que le sea imputable al docente para justificar la no renovación en el cargo.

La institución demandada, recurrió la decisión argumentando la violación de la autonomía universitaria (art. 75, inc. 19 de la CN) así como del artículo 29, inciso h, de la ley 24.521. Destacó que los actos administrativos atacados se encontraban alcanzados por la presunción de legitimidad y fuerza ejecutoria, y que habían sido emitidos en el ejercicio de atribuciones 
privativas e indelegables que le corresponden a la universidad en virtud de su autonomía académica e institucional.

La Corte, tomando los argumentos expuestos por la Procuración General de la Nación, entendió que lo que se hallaba en discusión era si el vínculo de las partes habilitaba al actor a exigir cierta estabilidad o permanencia en su cargo, una vez que venció el tiempo de su designación interina. Para resolver consideró cuáles eran las normas y principios que regulaban el caso, resultando determinante el carácter de institución universitaria nacional de la demandada, con la respectiva autonomía académica reconocida constitucionalmente, y la expresa competencia para fijar su régimen de administración de personal (art. 59 ley 24.521 y art. 72 de su Estatuto).

De tal regulación surge que el actor no puede pretender el derecho a permanecer en el cargo más allá del tiempo por el que fue designado o el que le permiten las normas vigentes, recordando que el nombramiento interino se extingue por el mero transcurso del tiempo previsto al momento de la designación, sin que se requiera el dictado de acto alguno por parte de las autoridades universitarias que así lo dispongan.

El argumento utilizado por el tribunal, refiere que; "asiste razón a la quejosa en cuanto sostiene que el a quo reconoció al docente una estabilidad que no correspondía otorgar a quienes se desempeñan interinamente $-y$ que ni aun aquellos profesores titulares, asociados o adjuntos nombrados por concurso pueden ostentar- toda vez que las designaciones en el cuerpo docente tienen un límite temporal en función del sistema clásico de periodicidad de las cátedras"

Como vimos, el presente caso no se resuelve por aplicación del Convenio Colectivo, posiblemente porque los hechos generadores del caso resultan anteriores a la sanción de dicha normativa y por la ausencia de planteo sobre su posible utilización como pauta de interpretación o guía.

Realizando el juego de intentar resolver el conflicto a la luz del vigente Convenio Colectivo, resultaría aplicable su 
artículo $73^{4}$, si es que el actor contara con cinco años o más de antigüedad como docente interino, debiendo la demandada incorporarlo a la carrera docente en vacantes definitivas de la planta estable. También resultaría aplicable la prohibición de modificar su situación de revista o condiciones de trabajo hasta que se resuelva su incorporación a la planta permanente.

Por otra parte, la Corte mencionó como un obstáculo al reconocimiento de los derechos esgrimidos por el actor la limitación temporal de los cargos docentes universitarios, en función del sistema clásico de periodicidad de las cátedras. Dicho modelo de estructuración de las funciones docentes universitarias se encuentra modificado por el Convenio Colectivo que en su capítulo III regula la "Carrera Docente" regulando el ingreso a la carrera docente (art. 11), la permanencia (art. 12), el ascenso y promoción (art. 13), la cobertura de vacantes (art. 14) y situaciones especiales (art. 15).

En el artículo 12 legisla respecto de la estabilidad en el cargo, al afirmar que; "La permanencia en el cargo que el docente ordinario o regular hubiere alcanzado estará sujeta al mecanismo de evaluación periódica individual que se establezca en

4 Art. 73: "Las Instituciones Universitarias Nacionales, a través de la Comisión Negociadora Particular, dispondrán los mecanismos para la incorporación a carrera docente de los docentes que revistan como interinos, y que a la firma del presente convenio tengan cinco años o más de antigüedad en tal condición, en vacantes definitivas de la planta estable. Hasta tanto se resuelva la situación de los mismos, no se podrá modificar en detrimento del docente, la situación de revista y/o condiciones de trabajo, por acción u omisión, a excepción del caso del docente que se encuentra comprendido dentro de las causales de cesantía 0 exoneración. Para el caso de los docentes que revistan como interinos, y que a la firma del presente convenio tengan entre dos a cinco años de antigüedad en tal condición, con vacantes definitivas de la planta estable, las Instituciones Universitarias Nacionales deberán cumplir con el procedimiento establecido en el art.11 del presente Convenio. No se podrá modificar en detrimento del docente, la situación de revista y/o condiciones de trabajo, por acción u omisión hasta la cobertura del cargo por concurso público y abierto de antecedentes y oposición; a excepción del caso del docente que se encuentre comprendido dentro de las causales de cesantía o exoneración. Quedan excluidos del presente artículo los docentes que se encuentren en la situación establecida en el artículo 6 inc. c (independientemente de su denominación) y en el artículo 15 del presente Convenio. En caso que la Comisión Negociadora de Nivel Particular no se encuentre constituida en la Institución Universitaria Nacional, se podrá requerir la intervención de la Comisión de Seguimiento e Interpretación" 
lasInstituciones Universitarias Nacionales. Dichas evaluaciones individuales se realizarán cada cuatro años o en un tiempo mayor según lo establecido en la reglamentación de cada Institución Universitaria Nacional. Cada una de las asociaciones sindicales docentes con ámbito de actuación en la Institución Universitaria Nacional en la que se lleve adelante la evaluación periódica, podrá designar un veedor gremial. En caso de obtener como mínimo dos evaluaciones negativas, el cargo será llamado a concurso público y abierto de antecedentes y oposición de conformidad a lo establecido en el art. 11, continuando el docente en el cargo hasta la cobertura por concurso."

Resulta entonces una solución judicial la aquí comentada, que desconoce la existencia del Convenio Colectivo de los trabajadores docentes universitarios.

\section{Derecho de los docentes universitarios a concertar convenios colectivos de trabajo (CSJN, "Biasizo")}

En este segundo precedente, el Tribunal nuevamente resolvió en contra de la petición del docente universitario accionante, pero -a diferencia del anterior- reconoció la validez de los convenios colectivos firmados entre las instituciones universitarias y los gremios representantes de los trabajadores. Adquiere además relevancia, pues, si bien en el caso se discutía la aplicación de un convenio colectivo anterior (Decreto $\mathrm{N}^{\circ} 1470 / 98$ ), la Corte tomó en cuenta la forma en la que regula la cuestión en debate el actual Convenio Colectivo homologado por Decreto 1246/15.

La acción declarativa de certeza en cuestión fue iniciada por un docente de la Universidad Tecnológica Nacional quien amparado en la ley 24.521 y el Estatuto de la UTN pretendía se declare la inconstitucionalidad del convenio colectivo de trabajo homologado por Decreto 1470/98, que establecía un límite horario total de carga docente.

5 CSJN, Fallos, 340:983, “Biasizo, Rogelio José c/ UTN s/ Empleo público”, sent. del 10-VIII2017. 
El conflicto a resolver se centró en la vigencia y alcances de lo establecido por el Decreto $1470 / 98$ que en su punto IV regulaba el régimen de incompatibilidades para el personal docente y en concreto disponía un límite a la cantidad de horas de labor semanal -50- dentro del sistema universitario. El actor planteó la inconstitucionalidad del referido decreto, por ser la actividad docente regida exclusivamente por la ley de educación superior -reglamentaria del artículo 75, inc. 19 de la CN- y por las normas que dictan las autoridades universitarias, en su caso Ordenanza 855/98 de la Universidad Tecnológica Nacional. Es decir, la cuestión regulada en el acuerdo homologado por el Poder Ejecutivo -en la visión del accionante- resulta materia reservada a las autoridades universitarias en virtud de la autonomía dispuesta en la Constitución Nacional.

Ingresó entonces el fallo en el contenido de la autonomía universitaria, entendiendo que implica libertad académica y de cátedra, así como la facultad de redactar sus estatutos, designar a los docentes y autoridades entre otras facultades (CSJN, Fallos 322:842, 919, entre otros). Sin embargo agregó que "por amplia que sea la autonomía consagrada por la reforma constitucional, ésta no deja de estar engarzada en el ordenamiento jurídico en general, sin que pueda sostenerse que la autonomía universitaria es por sí misma un poder en sentido institucional", por ello "toda la independencia que se quiera conceder a las universidades, siempre estarán sujetas a las leyes del Congreso".

La Corte federal sostuvo que "parece razonable que las universidades puedan disponer de las potestades necesarias para llevar a cabo su gestión respetando su contenido esencial, constituido básicamente por todos los elementos necesarios que hacen al aseguramiento de la libertad académica y la libertad de cátedra. Sin embargo, la facultad de dictar sus normas de funcionamiento interno no puede en modo alguno convertirse en un obstáculo al ejercicio de los derechos consagrados por la Constitución Nacional a favor de los trabajadores que se refieren a la asociación sindical libre y democrática y a la posibilidad de concertar convenios colectivos de trabajo (art. 14 bis)". 
Luego de recordar que las negociaciones colectivas del sector docente estatal fueron reguladas normativamente aún antes de la reforma constitucional de 1994 (Ley 23929, Decreto 1007/95, decreto 1470/98), consideró que en nuestro de sistema de convenciones colectivas de trabajo, el acto de homologación que aprueba lo acordado por las partes reviste una especial trascendencia jurídica ya que desde su dictado el convenio adquiere vigencia.

Por ello, concluye; "La regulación de las incompatibilidades del personal docente de las universidades nacionales mediante el convenio colectivo de trabajo que el Poder Ejecutivo homologó por el decreto 1470/98 no parece entrañar una afectación de la autonomía universitaria, ni una limitación a su potestad regulatoria, puesto que, en definitiva, permite que cada universidad establezca su propio régimen y sólo fija la máxima carga horaria que se le puede adjudicar a un docentes con miras a un óptimo desempeño académico.”

Finaliza los argumentos de tal decisión, agregando que "A mayor abundamiento, se advierte que por decreto 1246/2015 se homologó el Convenio Colectivo para Docentes de las Instituciones Universitarias Nacionales, en el marco de lo dispuesto por las leyes 11.672 (t.o. 2014), 23.929 y 24.938 y el decreto 1007/95, que regulan la negociación colectiva para los trabajadores docentes, cuyo art. 31, anexo I, contiene un precepto en materia de incompatibilidades similar al que impugna el actor en el sub examine.", concluyendo que "resulta inadmisible el agravio planteado por el actor en el sentido de que el régimen de incompatibilidades, a partir de la autonomía otorgada por la Constitución Nacional, sólo puede ser fijado por el Consejo Superior de las universidades nacionales, conclusión que impide alegar derechos adquiridos a desempeñarse en los cargos docentes obtenidos por concurso con base en tales alegaciones improcedentes." 


\section{Aplicación del Convenio Colectivo para Docentes de Instituciones Universitarias Nacionales (Cám. Fed. Corrientes, "Rodríguez")}

La actora, una docente de la Facultad de Ciencias Agrarias de la Universidad Nacional del Nordeste (UNNE), interpuso una acción directa contra una resolución del Consejo Superior de dicha entidad, solicitando se aplique el artículo 12 del Convenio Colectivo de Trabajo para docentes universitarios nacionales, que dispone que la permanencia en el cargo que el docente ordinario hubiere alcanzado estará sujeta a un mecanismo de evaluación periódica individual que establezcan las universidades que deberá realizarse cada cuatro años o en un tiempo mayor según lo establezca cada reglamentación. En síntesis peticionó que se aplique el convenio en cuestión, respetando así su derecho de ser evaluada cada cuatro años como mínimo y se deje sin efecto la designación por el plazo menor de dos años dispuesta por las autoridades de la Facultad y de la Universidad.

Según quedó acreditado en autos, la situación de revista de la Dra. Rodríguez era que se desempeñaba como personal de la planta permanente docente de dicha Facultad en dos cargos de Jefe de Trabajos Prácticos, uno de ellos con dedicación exclusiva y el restante con dedicación simple, contando a febrero de 2018 con una antigüedad reconocida de 25 años. También se corroboró que el Consejo Directivo procedió a renovar su designación -en el marco de una evaluación periódica docentepor el término de dos años, fundado en la resolución Consejo Superior $\mathrm{N}^{\circ}$ 956/09 que regula el régimen general de carrera docente de UNNE (Dispone su artículo 96 que la evaluación individual podrá realizarse cada dos o cuatro años). Esta decisión fue avalada por Resolución del Consejo Superior de la UNNE N 138/17.

6 Cámara Federal de Corrientes, "Rodríguez, Silvia Carlota c/Universidad Nacional del Nordeste s Recurso Directo Ley de Educación Superior Ley 24.521", expediente 5454/2018/ CA1, Sent. del 24-V-2019. 
La Cámara hizo lugar al planteo de la accionante advirtiendo que la resolución de la universidad recurrida no hizo mención del Convenio Colectivo No $1246 / 2015$, homologado en fecha 01/07/2015, que entró en vigencia al día siguiente de su publicación, en particular omitió contemplar lo expresamente dispuesto en sus artículos 2, 3, 6, 7, 12, 69, 72 у cc.

Así, para el caso de la designación bianual realizada luego de la entrada en vigencia del Convenio Colectivo (existía una designación anterior a dicha circunstancia) la universidad -si bien cumplió con el procedimiento de evaluación regulado por la propia entidad empleadora- vulneró derechos de la actora "toda vez que surge claramente que no se ha respetado el principio de aplicación en caso de concurrencia de normas establecido por el art. $72^{7}$ del CCT 1246/15".

En concreto la Cámara resuelve la contradicción entre las normas en conflicto, por otorgarle validez a la posterior y entender derogada a la previsión propia de la universidad. Dijo; "No resulta claramente justificada la aplicación de la Ordenanza de Carrera Docente (956/09) en su art. 96, el que da la opción de dos (02) o cuatro (04) años, en tanto el art. 12 del CCT 1246/15 establece “...Dichas evaluaciones individuales se realizarán cada cuatro (04) años o en un tiempo mayor...". Es justo remarcar que la primera rigió hasta la fecha 02 de julio de 2015, siendo modificada -en cuanto a norma más favorable al docente-, por la segunda, conforme al principio de aplicación ya explicitado".

En definitiva, entiende el tribunal que la deficiencia en la ley aplicable torna irrazonable el acto administrativo impugnado y, por lo tanto, tal vicio afecta su validez, correspondiendo ordenar a la UNNE que dicte un nuevo acto administrativo con arreglo a lo decidido ut supra.

\footnotetext{
7 Art. 72: "En caso de duda sobre la aplicación de normas de origen autónomo o heterónomo, incluyendo las provenientes del presente convenio, sean las mismas de aplicación en el ámbito de alcance general o particular de cada Institución Universitaria, considerándose la debida satisfacción del servicio, se aplicará la norma más favorable al docente."
} 


\section{Conclusiones}

En efecto, los tres fallos evidencian retrocesos y avances en el reconocimiento jurisprudencial de la vigencia del Convenio Colectivo para Docentes de las Instituciones Universitarias Nacionales, con una tendencia a favor de su validez. No caben dudas que los trabajadores docentes universitarios se encuentran protegidos tanto por los principios y derechos que establece el art. 14 bis de la Constitución Nacional, como por los tratados internacionales de derechos humanos y de protección del trabajador. Allí no sólo se reconoce al empleado público como trabajador sino que se refuerza con especial énfasis el principio protectorio al garantizarle la estabilidad en el cargo, protegiéndolo ante la posible arbitrariedad de su empleador público.

Respecto de la aplicación del Convenio, la tendencia es hacia su efectividad y vigencia en la relación laboral que auto reguló. La Corte Suprema de la Nación ha dicho al respecto que: "Los convenios colectivos de trabajo constituyen una manifestación típica y cualificante de la función autorregulatoria de las organizaciones sindicales y de empleadores frente a la realidad dinámica. Dicha tarea, mediante el ejercicio del consenso, y más allá de los mecanismos del mercado económico, deben apoyarse en principio de cooperación, solidaridad y justicia social a fin de promover el mantenimiento de la paz y el orden" (CSJN, autos "Repetto, Inés m c/ Provincia de Buenos Aires", sent.de fecha 31-X-1990).

Así, los Convenios Colectivos de Trabajo, si bien no son técnicamente leyes, sí son normas de derecho positivo cuya aplicación obligatoria proviene del texto expreso de la Constitución, Tratados Internacionales y de las propias leyes laborales. En el caso en estudio, se impone la aplicación y vigencia del Convenio Colectivo homologado por decreto 1.246/15. 